Pedagogía y Saberes n. ${ }^{\circ} 53$ Universidad Pedagógica Nacional Facultad de Educación. 2020. pp. 69-82

\title{
El saber escolar de las artes en la escuela pública (1850-1900)*
}

\section{Artículo de investigación}

School Knowledge of the Arts in the Public School (1850 - 1900) Saber escolar das artes na escola pública $(1850$ - 1900)

\author{
Óscar Leonardo Cárdenas Forero** \\ Marco Tulio Cárdenas Forero*** \\ Camila Andrea Hernández Castillo****
}

\section{Para citar este artículo:}

Cárdenas, O., Cárdenas, M. y Hernández, C. (2020). El saber escolar de las artes en la escuela pública (1850 - 1900). Pedagogía y Saberes, 53, 69-82. https://doi.org/10.17227/pys.num53-10554

* El presente artículo forma parte del proyecto de investigación en curso "Los saberes artísticos en la escuela pública colombiana de la segunda mitad del siglo XIX", avalado y financiado por la Universidad del Tolima.

** Magíster en Desarrollo Educativo y Social. Universidad Pedagógica Nacional. Bogotá, Colombia. Profesor Universidad del Tolima Abierta y a Distancia (Idead). Ibagué, Colombia. Grupo de investigación "Historia de las Disciplinas Escolares". Correo electrónico: olcardenasf@ut.edu.co. Código Orcid: orcid.org/0000-0003-4894-7888.

*** Magíster en Desarrollo Educativo y Social. Universidad Pedagógica Nacional. Bogotá, Colombia. Profesor Universidad del Tolima Abierta y a Distancia (Idead). Ibagué, Colombia. Grupo de investigación "Historia de las Disciplinas Escolares". Correo electrónico: mtcardenasf@ut.edu.co. Orcid: orcid.org/0000-0002-3124-3086.

**** Magíster en Desarrollo Educativo y Social. Universidad Pedagógica Nacional. Bogotá, Colombia. Profesora Universidad del Tolima Abierta y a Distancia (Idead). Ibagué, Colombia. Grupo de investigación "Historia de las Disciplinas Escolares". Correo electrónico: cahernandezc@ut.edu.co. Código Orcid: 0000-0001-6363-2329. 


\title{
Resumen
}

El presente artículo de reflexión cualitativa es una aproximación a la construcción de la historia del saber escolar de las artes en la segunda mitad del siglo XIX. Metodológicamente, empleó el enfoque arqueogenealógico de Michel Foucault y, enmarcado en el proyecto de investigación "Los saberes artísticos en la escuela pública colombiana del siglo XIX", continúa y complementa el trabajo iniciado sobre la construcción de la historia del saber de las artes en la escuela pública de la primera mitad del siglo xIX, analizando su desarrollo posterior, en términos de su procedencia, función y funcionamiento en la escuela pública entre 1850 - 1900. Con esto, se pretende dar cuenta de las condiciones históricas que impulsaron la introducción, instalación y constitución definitiva del saber de las artes como un saber escolar dentro de la estructura curricular pública; la transfiguración de los modos de la enseñanza escolar, y la forma en que fue asumido bajo el término de asignaturas académicas del dibujo, el canto y la música, que fueron empleadas como tecnologías de disciplinamiento, conforme con la racionalidad de la época, para encauzar los comportamientos de los sujetos escolares y su constitución como subjetividades dóciles, adiestradas y normalizadas. Para lograr este objetivo, se constituyó, en primera instancia, un archivo documental que luego fue recopilado en fichas de registro del que se rastrearon los vestigios y se determinaron las condiciones de poder que se instituyeron para impulsar la emergencia de estos, y de los cuales se extrajeron los enunciados, los espacios, los conceptos y los juegos de poder que permitieron analizar el objeto de estudio formulado.

\section{Palabras clave}

saberes escolares; saber de las artes; escuela pública; prácticas disciplinarias

\begin{abstract}
The present qualitative reflection article is an approximation to the construction of the history of school knowledge of the arts in the second half of the XIX century. Methodologically, it used Michel Foucault's archeo-genealogical approach and, framed in the research project "Knowledge Artistic Studies in the Colombian Public School of the XIX century", is a study that continues and complements the work begun on the construction of the history of knowledge of the arts in the public school of the first half of the xIX century, analyzing its later development, in terms of its origin, function and functioning in the public school between 1850-1900. At the same time, it pretends to portrait the historical conditions that prompted the introduction, installation and final constitution of the knowledge of the arts as a school knowledge within the public curricular structure; the transfiguration of the modes of school teaching, and the way in which it was assumed under the term of academic subjects of drawing, singing and music, which were used as disciplining techniques, in accordance with the rationality of the time, to guide behaviors of the school children and their constitution as docile, trained and normalized subjectivities. In order to achieve this objective, a documentary file was created and it was compiled in records sheets form which the vestiges were traced and the conditions of power that were instituted to promote their emergence were determined; and of which were taken the concepts, spaces, statements and power games that allowed analyzing the object of study formulated.
\end{abstract}

\section{Keywords}

school knowledge; artistic knowledge; public school; governmentality

\section{Resumo}

O presente artigo de reflexão qualitativa é uma abordagem para a construção da história do saber escolar das artes na segunda metade do século XIX, metodologicamente, utilizando a abordagem arqueológico-genealógica de Michel Foucault e enquadrada no projeto de pesquisa "Os saberes Artísticos na Escola Pública Colombiana do século XIX", é um estudo que continua e complementa o trabalho iniciado na construção da história do conhecimento das artes na escola pública da primeira metade do século XIX, analisando seu desenvolvimento posterior, em termos de origem, função e funcionamento na escola pública entre 1850 e 1900. Ao mesmo tempo, pretende realizar as condições históricas que levaram à introdução, instalação e constituição definitiva do saber das artes como um saber escolar dentro da estrutura curricular pública; a transfiguração dos modos de ensino escolar e a maneira como foi assumida, sob o termo de disciplinas acadêmicas de desenho, canto e música, que foram utilizadas como tecnologias disciplinadoras, de acordo com a racionalidade da época, para orientar comportamentos dos alunos escolares e sua constituição como subjetividades dóceis, treinadas e normalizadas. Para atingir esse objetivo, foi criado, em primeira instância, um arquivo documental, o qual foi compilado em fichas de registro a partir das quais os vestígios foram traçados e foram determinadas as condições de poder instituídas para promover seu surgimento; dos quais foram extraídos os conceitos, os espaços, as falas e os jogos de poder que permitiram analisar o objeto de estudo formulado.

\section{Palavras chave}

saber escolar; conhecimento das artes; escola pública; governamentalidade 


\section{Preámbulo}

En 2019 se publicó el artículo "La historia de los saberes artísticos en la escuela pública colombiana en la primera mitad del siglo XIX" (Cárdenas y Cárdenas, 2019), documento en el que se dieron a conocer las diversas condiciones históricas ocurridas durante el periodo 1800-1850 que, articuladamente y ensambladas a un dispositivo de poder, posibilitaron la introducción del saber de las bellas artes en la estructura de los planes de enseñanza de la escuela pública, transfigurando su función y su manera de operar en la época.

Como complemento de este abordaje, se realizó el presente estudio a través del cual se pretendió describir las condiciones históricas que posibilitaron la instalación decisiva del saber escolar de las bellas artes en la estructura curricular de la escuela pública (1850-1900). Se buscó explorar su génesis, función y funcionamiento y, con ello, su configuración como una tecnología de sometimiento que determinó la conducta subjetiva en función de un modelo legitimado.

Para este ejercicio de exploración histórica, el investigador adoptó el papel del arqueólogo, quien "se dedica a extraer los acontecimientos discursivos como si estuvieran registrados en un archivo" (Foucault, 2017, p. 743). Una vez ejecutada esta actividad, el investigador se viste del ropaje gris del geneálogo, quien explora en la historia los juegos de poder y las "condiciones de emergencia de un acontecimiento" (Martínez, 2004, p. 37).

Este análisis arqueogenealógico permitió rastrear, en la segunda mitad del siglo XIX, las condiciones históricas que impulsaron la instauración definitiva del saber de las artes en la escuela pública, y su posibilidad de ser legitimado como un saber enseñable en los planes de estudio de la época. Y con ello, determinar su función, procedencia, funcionamiento y la forma de contenidos que asumió, asociados al dibujo, la música y el canto, que, a la vez, se empleó como una estrategia de poder para orientar los modos de constitución de los sujetos escolares.

Durante la segunda mitad del siglo XIX, el saber de las bellas artes se consolidó como un ramo de instrucción pública en la forma de una serie de materias escolares (dibujo, canto y música), en la organización curricular de la escuela y como una tecnología de disciplinamiento utilizada para configurar, de un modo particular, a los sujetos escolares y adiestrar sus comportamientos, acciones y valores, conforme a las reglas de funcionamiento de la racionalidad de la época.
En esta medida, el saber de las bellas artes se constituyó en una técnica de poder dirigida a lo que Foucault (2004) denominó la normalización disciplinaria, es decir, un ejercicio del poder en el que se analiza y descompone a los sujetos escolares con el objeto de modificarlos, normalizarlos, someterlos, clasificarlos e instruirlos con base en unos objetivos establecidos y en "un modelo óptimo que se construye en función de determinado resultado" (p. 75). A través de dicha normalización, se fijan aquellos contenidos a enseñar, comportamientos a seguir, los procedimientos y mecanismos de control constante que actúan sobre sus conductas, y que, al mismo tiempo, las ajustan, amoldan y adecuan, precisamente, a la norma instaurada (normación).

Precisamente, a finales de la segunda mitad del siglo XIX, uno de los significados con el que se designaba el saber de las artes era el de las bellas artes. De manera que se constituyó en un saber liberal y aristócrata reservado para la educación y enseñanza de las élites de la población del país; en particular, para las Casas de Educación Privadas, que convivió, antes de ser escolarizado en la escuela pública, con aquella concepción del saber de las artes que lo asociaba al trabajo del artesanado, de los zapateros, albañiles, sastres, herreros, entre otros, en otras palabras, un saber profano y exclusivo de las clases pobres y los sectores de la nación.

No obstante, resultado de la convergencia de diversas condiciones, estas concepciones sobre el saber de las artes comenzaron a distanciarse. En 1849, por ejemplo, en el periódico El Museo (1849), de Bogotá, apareció un artículo en el que se manifestaba la necesidad de diferenciar el significado de ser artista y ser artesano. En dicha publicación se enunció que a pesar de que las dos palabras se derivaban del sustantivo arte, no se sabía:

[...] en qué se funden para creer que la idea espresada por la primera sea mas lata de lo que realmente es, o que equivalga a la espresada por la segunda. Ni por sus respectivas terminaciones, que indican cada cual el uso que de ellas debe hacerse ni por las definiciones que da el Diccionario de la lengua, pueden confundirse estas dos vozes (p. 18).

Así, se fueron diferenciando dos conceptos claves para entender estas subjetividades instaladas en la época. Por un lado, el artesano es aquella persona que "ejercita algun arte mecánico" (p. 18), mientras que el artista "estudia el curso de artes-Liberalium artium sodalis alumnus" (p. 18). Es más, también se sostuvo que el artesano podía ser: 
[...] un idiota, un imbécil; [...] el artista tiene que salir de la esfera vulgar i elevarse sobre el comun de las jentes: necesita un alma grande, capaz de comprender la naturaleza i apreciar sus sublimes bellezas para imitarlas; en él todo es poesía, todo espiritualismo; en el otro todo es prosa; su humilde oficio está mui lejos de exijirle otra cosa (p. 18).

Debido a ello, la distinción entre el sujeto artista y el sujeto artesano significó una escisión entre las artes relacionadas con el oficio del artesanado, considerado como un saber mecánico, rutinario y monótono, alejado de la inventiva humana, de la posibilidad de crear. Por su parte, el saber de las artes, propio del artista, implicaba creación e inventiva, las bellas artes y liberales que se asociaron a la música, pintura, escultura y grabado. Dicha diferenciación permitió develar la tensión entre la influencia de ciertas tendencias de carácter humanista en el saber de las artes, situación que contribuyó a la construcción y despliegue del proyecto ilustrado y emancipatorio; también, a aquellas perspectivas de carácter pragmático que lo consideraban como un saber escolar poco útil para los propósitos de desarrollo y crecimiento económico del país y, por supuesto, en la formación de los sujetos productivos que la época requería.

Visto esto, el saber de las artes comenzó a diferenciarse entre aquella idea que lo relacionaba con los oficios, labores y tareas que realizaban los artesanos y sus aprendices en los talleres artesanales, con los modos de hacer en la carpintería, herrería, talabartería, entre otros, y aquella que lo asociaba con las bellas artes (dibujo, música y canto), un saber culto, reservado "para otras educaciones, las privadas y de saber élite, útiles y determinadas para las gentes cultas de la sociedad" (Cárdenas y Cárdenas, 2019, p. 181). Por ese motivo, en determinado momento de la historia del país estuvo por fuera de la escuela pública, buscando ocupar un lugar dentro de la estructura curricular y de las estrategias de la instrucción pública.

Un ejemplo de eso aparece enunciado en el marco del Plan de las Escuelas Patrióticas, que se comenzó a publicar en el periódico Semanario del Nuevo Reyno de Granada (13 de marzo de 1808). En él se propuso la enseñanza del saber de las artes como una estrategia para mejorar el juicio y discernimiento de los niños, así como, conseguir "cultivar la armonía, la imaginación, la sensibilidad, las pasiones, el buen gusto, la belleza y acercarlos a la contemplación de la naturaleza" (Cárdenas y Cárdenas, 2019, p. 178).

Posteriormente, el saber de las artes (en la forma de la música, el canto y el dibujo) prosiguió en su intención de ocupar un lugar en los programas de enseñanza públicos. Es decir, curricularizarse e ins- talarse generalizadamente como un conjunto de contenidos a considerar en la instrucción y como un mecanismo de disciplinamiento dirigido a la formación de unos alumnos singulares en la escuela pública.

Así, para finales de la primera mitad del siglo XIX, se dispusieron las condiciones para que no solo se diferenciaran de una manera marcada las artes asociadas al trabajo mecánico y rutinario del artesanado, y las bellas artes relacionadas con el trabajo ingenioso del artista, sino para que se introdujera y escolarizara en el modo de las materias académicas del dibujo, canto y música en la escuela pública, en particular, a través de las Escuelas Normales. Y, de esa manera, hacer parte de su organización curricular y de las tecnologías de dominación empleadas para el adiestramiento infantil y el encauzamiento de sus conductas conforme con el modelo histórico instaurado.

\section{Los saberes escolares como tecnologías de disciplinamiento}

En Tecnologías del yo, Foucault (1990) hizo referencia a la existencia de cuatro tipos principales de tecnologías - aquellos medios calculados y utilizados "razonadamente para que las personas se comporten de acuerdo con unos objetivos trazados de antemano" (Castro-Gómez, 2015, p. 37)—, que se emplean en cada una de las épocas para que las acciones de intervención sobre los individuos cumplan determinados fines conforme con la racionalidad implantada.

Entre ellas se destacan las tecnologías de poder "que determinan la conducta de los individuos, los someten a cierto tipo de fines o de dominación" (Foucault, 1990, p. 48), a través de las cuales se los normaliza disciplinariamente; se los norma, objetiva, sujeta, singulariza, modifica y ajusta de acuerdo con los modelos establecidos en un momento determinado. Justamente, la enseñanza del saber de las artes se convirtió en una de las tecnologías de poder que se empleó para conducir y someter de manera calculada y estratégica los comportamientos y la constitución de los sujetos en la escuela hacia la elevación de su espíritu sensible, junto con el reconocimiento de la armonía y la belleza en la naturaleza.

Ahora bien, para Chervel (1991), los saberes escolares en el tiempo de existencia no siempre han tenido la misma estructura, propósito y funcionamiento dentro de la escuela. En un principio, estuvieron orientados a la gimnasia intelectual de los aprendices, pero también, al disciplinamiento, corrección y ajuste de aquellas conductas que estuvieran por fuera del orden establecido. Singularmente, el saber de las artes en la segunda mitad del siglo xIX en el 
país se orientó a adiestrar los comportamientos de los sujetos escolares y a censurar aquellos que afectaban lo legítimamente instaurado, con el objeto de constituir subjetividades escolares ilustradas y ajenas a la ignorancia.

En ese sentido, los saberes escolares durante el siglo XIX se introdujeron, constituyeron y consolidaron en la escuela pública como tecnologías de disciplinamiento; que, como campo estratégico y material de las prácticas de normalización y sometimiento, obedecieron al funcionamiento de la época con unos objetivos establecidos, medios y estrategias singulares. En consecuencia, se orientaron a normar y encauzar las conductas de los sujetos escolares y producirlos de un modo particular.

De esa manera, se instalaron como mecanismos de poder sobre las acciones de quienes asistían a la escuela pública. A saber, ejercicios de normalización enfocados a someter la voluntad de los sujetos escolares y a vigilar continuamente sus actuaciones para hacerlas concordar con los requerimientos establecidos.

Estos hechos validan no solo que los saberes escolares irrumpieron en la escuela pública decimonónica para constituirse en técnicas de disciplinamiento y sometimiento subjetivo, sino que los saberes escolares se configuraron en emergencias históricas y sociales, invenciones en el tiempo susceptibles de perdurar, modificarse o diluirse; pues funcionan ensambladas a las condiciones particulares de cada coyuntura histórica, las cuales se transforman, acomodan y despliegan continuamente.

En consecuencia, no son creaciones inmóviles acordes con el avance de las sociedades para procurar algo mejor para la población o a la voluntad de algún sujeto, institución, política educativa, libro de texto u orientación legal interesado en hacer de la escuela y sus planes de estudio un asunto innovador. Por el contrario, son fluctuaciones polimórficas que intervienen en la escuela para devenir en sujetos acordes con la racionalidad instaurada.

Esto permite reconocer que los saberes escolares no son condiciones naturales propias de la estructura curricular de la escuela, materializaciones dadas y preestablecidas. Tampoco son evoluciones efecto del progreso escolar, de la invención de los maestros, y mucho menos de los avances provocados en algún campo de las ciencias de la educación o de la pedagogía, con sentidos, propósitos, funciones y maneras de operar similares, que en el tiempo permanecen sin modificación alguna en el marco de la organización escolar.
No son simples amalgamas inmóviles que se mantienen en cada época, como lo señaló Goodson (1991), que perduran inamovibles sin sufrir alteración alguna, ni vulgarizaciones o adaptaciones del conocimiento producido en las comunidades científicas, sino que son fluctuaciones con multiplicidad de rostros, formas y concepciones que se articulan a cada coyuntura de la historia. A través de ellas es factible dar cuenta de los modos como la enseñanza escolar se instituye, sus contenidos de enseñanza, recursos, metodologías, didácticas, y hasta de la misma escuela, el maestro y los intereses de la sociedad respecto a la educación y la escolarización.

\section{La racionalidad educativa a mediados del siglo XIX y el saber de las bellas artes (1850-1900)}

A comienzos de la década de 1850, la racionalidad educativa neogranadina instaurada se enfrentó a la irrupción de una multiplicidad de reformas de carácter liberal radical que se tradujeron, entre otras políticas, en la permisión de la libertad de enseñanza. Según Zuluaga (1998), esa libertad consistió en la facultad que el Congreso de la República de la Nueva Granada le concedió a todos los ciudadanos "de adquirir la instrucción literaria y científica en establecimientos públicos, privados o de particulares, con el objeto de recibir grados académicos" (p. 165).

Esta reforma radical posibilitó la transformación de la manera de ser de la instrucción pública e impulsó la introducción de aquellos ramos de enseñanza que no se opusiera a la moral, las buenas costumbres o las leyes del momento. Adicionalmente, se validó y legitimó con la promulgación de la Ley de mayo de 1850 sobre instrucción pública, en la que "quedó consagrada la libertad de enseñanza en todos los ramos de las ciencias, las letras y las artes" (Zuluaga, 1998, p. 182).

Justamente, la libertad de enseñanza, comprendida como una estrategia que facilitó impartir cualquier tipo de catedra sin desconocer los principios morales, de crecimiento económico y los de nación, se convirtió en una posibilidad para introducir e institucionalizar diversos saberes escolares en la escuela. Entre ellos, el saber de las artes en la forma de los ramos de instrucción asociados al canto, la música y el dibujo; a saber, a las bellas artes, empleados en los procesos de formación, adiestramiento y regulación de los comportamientos de los sujetos en la escuela, convirtiéndose en tecnologías de disciplinamiento a través de las cuales se pretende la singularización de los individuos (Castro, 2011, p. 102). 
Por ello, a finales de la primera mitad del siglo XIX, aprender "á escribir, á leer, aritmetica, principios de gramática y doctrina" (El Constitucional, 3 de octubre de 1846), se constituían en los ramos de instrucción establecidos en la escuela pública como fundamentales para la enseñanza, el proyecto nacional y la formación de la población. Los cuales se aprendían de acuerdo con los métodos prescritos (enseñanza mutua). En particular, el saber de las artes comenzaba a asociarse con la capacidad para:

[...] reunir lo mas agradable, lo mas interesante que la naturaleza produce, empleando sus mismos medios y recursos; en reunir en un cuadro estrecho los primores que ella esparce en sus paisajes; en producir un nuevo conjunto en que no se eche ménos la armonía ni la unidad; en hermosear, por fin, un sitio risueño i bien escojido, sin adornos superfluos ni complicados (El Constitucional de Cundinamarca, 1848, p. 3).

De igual manera, se insinuaba como un ramo de instrucción a considerar las áreas del dibujo, la música y el canto en la estructura escolar pública, en particular, en las instituciones educativas para niñas. Véase, por ejemplo, cómo en el Colegio de La Merced se decretó, según la Ordenanza 117 promulgada por la Cámara Provincial de Bogotá en 1850, la enseñanza de diversos ramos, entre los que se encontraba el "dibujo lineal i de flores i paisajes; [...] i música instrumental i vocal" (El Constitucional de Cundinamarca, 1850, p. 3). Estos se emplearon para apoyar la formación y aprendizaje de las niñas, con el fin de orientar y regular sus comportamientos y maneras de constituirse como sujetos escolares obedientes, adiestrados y sometidos a las reglas de funcionamiento de la época.

Cabe señalar que, desde la publicación de Manual de Enseñanza Mutua para las Escuelas de Primeras Letras, de José María Triana (1845), se divulgó la importancia de la enseñanza del canto en ese proceso de formación humano, pues: "la naturaleza siempre pródiga ha dado á todos un instrumento el mas dulce, harmonioso i variado, -la voz o el canto. Ella conmueve como se quiere el alma é imita todos los tonos que pueden formarse con los instrumentos inventados" (p. 58). Por tanto, se consideró trascendental, enseñarles "a los niños á servirse de un instrumento que nada les cuesta i que los acompaña á todas partes" (p. 58).

Como se advierte, se justificó en los discursos de la época la inclusión del dibujo, la música y el canto como saberes de las artes en los planes de estudio de la escuela pública, en la medida en que contribuirían en la formación cultural e intelectual de los grana- dinos sin importar su condición social y económica. Ya desde de 1850, el país apostaba por votar una ley sobre la instrucción pública, que "pusiera al proletario en capacidad de recibir una instruccion sólida, $\mathrm{i}$ provechosa, sin mas trabajo que la que recibiera el hijo del capitalista" (El Ciudadano. Periódico de la Juventud, 1850, p. 3).

\section{El dibujo como nueva materialización del saber de las bellas artes en la escolarización (1850-1870)}

En el Manual para preceptores de enseñanza primaria, e instrucción moral i religiosa, redactado, de José María Triana (1851), el saber del dibujo apareció asociado al dibujo lineal, en la forma del diseño lineal, considerado como:

1.- [...] el arte de representar por simple rasgo los diferentes objetos de la industria i de las artes.

2.- Desde el nacimiento está obligado á indicárselas con un rasgo, negro ó rojo, diseñado sobre una plancha, una pared ó un papel; el platero, el joyero, que adornan sus obras con, piezas adjuntas, emplean el diseño ó un rasgo para esplicar los adornos que los obreros deben ejecutar. En fin, en la mayor parte de los estados industriales los maestros pasan un trazo geométrico con la regla i el compas, ó solo con el lápiz cuando quieren hacer un bosquejo (p. 202).

En ese sentido: "el diseño lineal debia hacer hoi parte de toda instruccion primaria i secundaria" (p. 202). Por ello su estudio e inclusión en los planes de instrucción de la escuela pública primaria facilitaba y conducía a que los alumnos aprendieran a diseñar, a realizar sus propias creaciones, pues esto daba: "gran facilidad [...] para hacer construcciones geométricas en el tablero" (p. 202).

Años después el dibujo lineal comenzó a tomar distancia y a diferenciarse del dibujo "perspectiva y de paisaje" (Ortiz, 1853, p. XIX), reservado para los colegios de las niñas, para instaurarse como uno de los saberes de las artes a considerarse en la enseñanza en el país; un ramo de instrucción propio de los hombres cultos, cuya utilidad esencial e importancia radicaba en ejercitar la vista, acostumbrar a observar situaciones, los detalles y formas de los objetos, así como, medir las distancias y apreciar las proporciones. Con ellos se reconocía que el dibujo perspectivo antecedía al dibujo práctico y, por consiguiente, el dibujo, al igual que la música, se debía enseñar en la escuela a los alumnos por medio de la imitación 
pues, esta manera de proceder en el salón de clases les facilitaba una copia fiel y una reproducción exacta y conforme con la realidad observada.

Por tal motivo, a un niño:

[...] debe ántes de hacerle ejecutar la menor cosa en diseño, habituarlo á comparar i juzgar la copia de un objeto regular i simple. Para tener una idea del dibujo, para apreciar sus ventajas es menester que el niño vea dibujar, que él sienta la utilidad de este arte, para que lo estudie con placer i con fruto. En general nada se debe enseñar á los niños, sin haberles esplicado i hecho sentir los motivos. Se comenzará, pues, por dibujar con rasgos sencillos, objetos usuales, como una caja, una cruz, en fin, una figura rectilínea regular. Si se prefiere, se hará ántes otra copia, en la cual el niño reconozca al instante el objeto representado. Tomando despues la copia por modelo, se imitará con mas ó ménos esactitud, i se hará que el discípulo la juzgue, quien encontrará tanto mayor dificultad, cuanto el objeto esté compuesto de mayor número de líneas diversas. Entónces es que se le hará observar que las líneas de que se componen las figuras son mas difíciles para juzgar en conjunto que separadamente; de donde él mismo conocerá la necesidad de ejercitarse desde luego en la ejecucion de las simples líneas, i en formas ménos complicadas, lo que hará con mas placer conociendo estos ejercicios elementales, cuyo objeto no habría conocido, si no le hubiera interesado (Triana, 1851, p. 203).

Así, el dibujo de paisaje se dirigió hacia la enseñanza de contenidos relacionados con

Eleccion del sitio -Diseño de masas -Los árboles pueden ser considerados como sólidos -El paisaje comprende el dibujo de los órdenes de arquitectura. Elementos del paisaje: dibujo de hojas, piedras, troncos de árboles, follaje de árboles. Cielo i aguas -Paisaje histórico -Marinas. Uso del lápiz de plomo -Uso de los dos lápices. Pintura a la aguada (Ortiz, 1853, p. 524).

Como se ve, el saber del dibujo impulsó la constitución de una subjetividad escolar a la que se le enseñó (y aprendió) a captar de la naturaleza observada lo cautivador y seductor, lo susceptible de ser imitado fielmente, lo bello, equilibrado y armonioso, que provocaba fascinación, deleite, gusto y armonía.

\section{La música, otro ramo del saber de las bellas artes incorporado en la escuela pública}

Adscrito al saber del dibujo, la música se concibió como un saber de las bellas artes enfocado a "conmover el ánimo con fuerza i entusiasmo i ablandarlo con sentimientos delicados i placenteros" (Ortiz, 1853, p. 306) de los pobladores, que "pone el alma en equilibrio, i le comunica el sentido de la armonia en todas las cosas" (Los RR, 1867, p. 1). Por ello, su estudio contribuía a desenvolver "el sentimiento de lo bello i abre al pensamiento horizontes totalmente desconocidos" (p. 1). En tanto que su enseñanza aportaba a formar subjetividades sensibles y apasionadas por lo bello y armonioso, para lo cual se apoyó en manuales escolares como Lecciones de música precedidas de una introducción histórica, seguida cada una de su respectivo programa, i acompañadas de láminas litografiadas elaboradas por Alejandro Agudelo (1858), un texto en el que se presentó una serie de contenidos de enseñanza para la formación musical de las personas.

Ahora bien, en 1856, durante el certamen de la escuela primaria del distrito parroquial de Tasco (Boyacá), dirigida por el cura párroco Indalecio Barreto, en el programa de las materias de enseñanza que los alumnos ofrecían, dedicaban y consagraban en certamen público al señor gobernador de la provincia de Tundama, Dr. Antonio Valderrama, se señaló que en la Escuela de Canto y Música auspiciada por el señor Andrés Castañeda, los alumnos Juan Higuera, Lauro Melgarejo y Pastor Hernández debían presentar y exhibir en este evento público no solo sus planas de escritura, que habían adquirido, sino exponer la teoría de la música y su conocimiento acerca de las figuras de diverso valor. Aquellas que se emplean para formar otras, los signos equivalentes, el punto simple y doble y su valor, las llaves, el orden para nombrar las notas, los instrumentos que sirven para las llaves, como también:

\section{[...] el efecto del sostenido i del doble bemol. -Cuan- tos son los compases i valor de cada uno de ellos, (los marcarán) -Cantarán las escalas en las llaves de sol i fa. -Espresarán los tiempos que vale cada nota i sus aspiraciones. -Cantarán semibreves, mínimas, semínimas, corcheas, i semicorcheas. -Lecciones de puntillo i lecciones en cada llave. -Terceras, cuartas, quintas \&, en mínimas, semínimas i corcheas. Can- tarán a duo algunos himnos i tocarán en el piano varias piezas (Barreto, 1856, pp. 7-8).}

Todo esto condujo a que se mantuviera el fomento no solo de la instrucción pública como la estrategia para la formación de la población neogranadina y el establecimiento del proyecto republicano, sino como uno de los mecanismos para apoyar la formulación de una estrategia a través de la cual se desplegara e introdujera el saber de las artes en la escuela pública como un ramo de instrucción orientado hacia la formación de alumnos que aprendieran a apreciar la belleza y la perfección musical. 
En esta medida, la música se concibió como "el arte de combinar los sonidos de manera agradable al oído" (La música, 1858, p. 29). Los sonidos, al producirse de modo simultáneo, constituían una melodía y sucesivamente una armonía.

No obstante, a pesar del oscurecimiento que tuvo el saber de las artes en la escuela años después, efecto de la guerra civil ocurrida entre 1861 y 1864, liderada por Mariano Ospina para derrocar al general Tomás Cipriano de Mosquera, y en la que "las condiciones de orden público provocaron entonces, que el código de instrucción dejara de aplicarse" (Zuluaga, 1998, p. 351), generó que las escuelas fuesen abandonadas y, por supuesto, que los planes escolares y aquello que se estaba enseñando se interrumpiera. Para 1865, durante el gobierno del presidente Manuel Murillo Toro, la instrucción pública se enfocó en garantizar los derechos individuales y la libertad de ejercer cualquier arte, para lo cual, se debía apostar por la formación de unos niños a quienes se les imprimieran los principios del honor, vergüenza, probidad, aseo, orden y se les enseñara la propiedad en todas las cosas, se les acostumbrara a la decencia y formara el buen gusto (Pinzón, 1864, p. 9), aspecto en el que el saber de las bellas artes iba a tener un papel primordial y necesario. Para esto, se empleó como estrategia la enseñanza de canciones como "CANCIONES DE EDUCACION AL SER SUPREMO [...], A LA VIRTUD [...], A LA AMISTAD [...]" (p. 10). Según Vargas de la Rosa (1882):

La música reune todo lo que hay de más tierno, apasionado, inefable o doloroso, y tiene acentos para todos nuestros goces y quejas para todas nuestras penas. [...] adormece á la infancia, electrizar á la juventud, reanima á la vejez, excita el valor, calma la cólera, suaviza las costumbres y dulcifica la vida (p. 4).

En otras palabras, fue el artilugio con el cual se impulsó la formación y gobierno de niños hacia el aprendizaje de buenas acciones y aquellas que tenían que ver con el aseo, la limpieza, la proporción y por supuesto, el buen gusto, y con ello, la constitución de una sociedad en estado de paz, libertad y seguridad, en la que el apoyo y el fomento del saber de las bellas artes, se constituyó en un hecho fundamental para lograrlo.

\section{El canto, saber de las bellas artes, adscrito a la música durante la segunda mitad del siglo XIX}

Otra de las formas que adoptó el saber de las artes fue el canto, comprendido como la voz más elocuente del ser, pues penetraba los oídos para descender al corazón: "i llega al corazon para encender en nuestra alma el fuego beatífico de los bienaventurados" (Her- nández, 1868, p. 121). También, como el vehículo para expresar nobles sentimientos, un "grito arrancado a nuestros espíritus, puede ser un himno de alegría, o de la deprecacion lastimosa del dolor" (p. 121).

Frente a este devenir, la música y el canto aparecían como saberes instaurados en escenarios distintos a la escuela, justificaban su importancia en la vida social de la época, lo que se constituyó posteriormente un discurso para favorecer su presencia, enseñanza e incursión en espacios de carácter educativo y escolar. Además, como una estrategia para "formar hombres sanos de cuerpo y espíritu, dignos y capaces de ser ciudadanos y magistrados de una sociedad republicana libre" (La Escuela Normal, 1871, p. 4). En ese sentido, el canto fue reconocido como un saber, susceptible de ser escolarizado, ya que contribuía a la formación de sujetos sensibles que aprendieran a expresar sus emociones y sentimientos a través de las voces y canciones, que reconocieran en él, un mecanismo para manifestar sus deseos, desconciertos, expectativas y necesidades.

La enseñanza del canto y la música, entonces, se insinuó en la escuela pública con la intención de formar patriotas y buenos cristianos, conforme al proyecto de Estado-nación y el deseo de forjar una identidad y espíritu nacional. Por esa razón, empleó como estrategia la enseñanza obligatoria de cantos patrióticos, tonadas e himnos alusivos a la libertad e independencia republicana

\section{El saber de las bellas artes (1870-1880)}

En 1870 se publicó el Decreto Orgánico de Instrucción Pública con el que se buscó fomentar la instrucción primaria, la uniformidad de los textos escolares y la formación de ciudadanos en los principios liberales. Con esta publicación se institucionalizó la enseñanza del canto, la música y el dibujo en la escuela pública dentro de las Escuelas Normales ${ }^{1}$ a manera de ense-

1 En la Escuela Normal para Varones del Estado Soberano de Cundinamarca, dirigida por el señor Ernesto Hotschick, determinada a convertirse en el modelo de los establecimientos públicos del país, en la que se ejercitaran tanto a los alumnos-maestros sobre la práctica de la pedagojia. El director de la escuela era el encargado de las lecciones de música y canto quien, justamente, dirigió la primera escuela primaria anexa a la Escuela Normal en la que los niños aprendían, entre otras materias, "nociones de música" (Cuarto Informe actual del Director de Instrucción pública del Estado Soberano de Cundinamarca presentado al Congreso de la República en sus sesiones ordinarias de 1874 , p. 11), en piano de siete octavas y dibujo, utilizando gruesas de cuaderno de dibujo y con cartones con muestras de dibujo. Del mismo modo, en la Escuela Normal de Mujeres, a la directora Catalina Recker, graduada del Reino de Prusia, se le encargó de la enseñanza del canto y la música, mientras que a la subdirectora Joaquina Arénas se le encargó de la geometría aplicada al dibujo. 
ñanzas superiores, que inicialmente habían sido planteadas en las escuelas primarias anexas y luego en las demás escuelas públicas en las que comenzaron a ingresar los institutores e institutoras (antes alumnos - maestros y alumnas - maestras). En la figura 1 se detallan las materias de enseñanza, entre los que se encontraban dibujo, música vocal e instrumental, que se brindaban a las alumnas/maestras en la Escuela Normal para mujeres; y en la figura 2, los contenidos enseñados en las escuelas anexas.

Figura 1. Relación de las materias de enseñanza de las escuelas anexas en 1874

\begin{tabular}{|c|c|c|c|c|}
\hline BNSENANZAS & PROFBSORES. & DraE, & HORAS. & ALUTNAS. \\
\hline 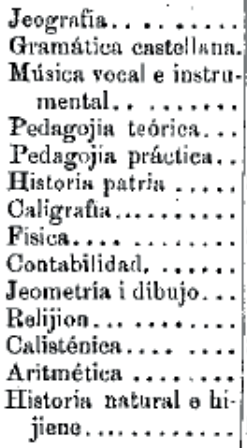 & 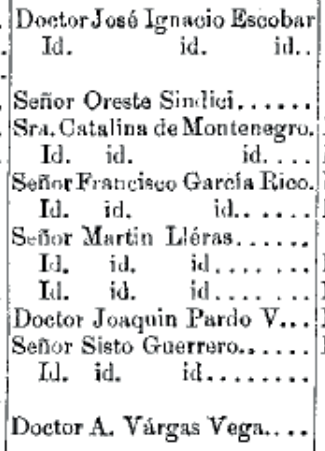 & $\begin{array}{l}\text { Diaria. } \\
\text { Diaria. } \\
\text { Diaria. } \\
\text { Lúnes, miérecles i viérnes. } \\
\text { Mártes, juéves i sábado.. } \\
\text { Mártes, juéves i sábado.. } \\
\text { Lúnes, miéreoles i viêrnes. } \\
\text { Diaria. } \\
\text { Lúnes, miércoles i viérnes. } \\
\text { Mártes, juéves i sábsido. } \\
\text { Mártes, juéves i sábado.. } \\
\text { Lúnes, miêrcoles i viérnes. } \\
\text { Diaria. } \\
\text { Diaria. }\end{array}$ & 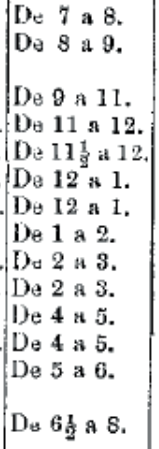 & $\begin{array}{l}\text { Todas. } \\
\text { Tudas. } \\
\text { Ménos } 4 . \\
\text { Tudas. } \\
\text { Iid. } \\
\text { Id. } \\
\text { It.l. } \\
\text { Ménos } 3 . \\
\text { Tudas. } \\
\text { Id. } \\
\text { Id. } \\
\text { Id. } \\
\text { Id. } \\
\text { I2 }\end{array}$ \\
\hline
\end{tabular}

Fuente: Cuarto Informe actual del Director de Instrucción pública del Estado Soberano de Cundinamarca (1874, p. 10).

Figura 2. Relación de las materias de enseñanza de las Escuelas Superior, Media e Inferior, 1874

BSCURLA STPPBRTōR (26 ALUMNOS).

\begin{tabular}{|c|c|c|c|}
\hline ENSEF゙ANZAS. & DI A 8 . & tho a As. & $\begin{array}{l}\text { ENTEADA } \\
\text { I SALIDA. }\end{array}$ \\
\hline 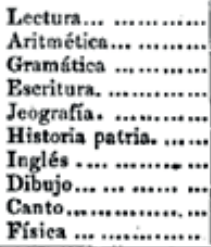 & 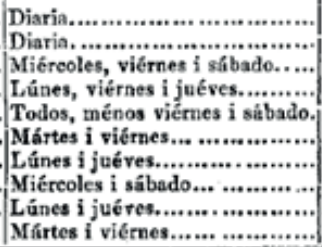 & 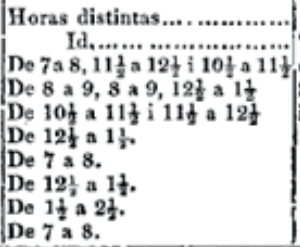 & $\begin{array}{l}\text { Entran a las } \\
7 \mathrm{i} \text { a las } 10 \frac{1}{2} \\
\text { do lamañana. } \\
\text { Salida a las } 9 \\
\mathrm{i} \text { a las } 2 \frac{1}{2}\end{array}$ \\
\hline
\end{tabular}

ESCURLA MÉDIA (46 ALUMNOS).

\begin{tabular}{|c|c|c|c|}
\hline EKBEKANzAs. & DIAS. & HORAs. & $\begin{array}{l}\text { Z STRADA } \\
1 \text { SALIDA. }\end{array}$ \\
\hline 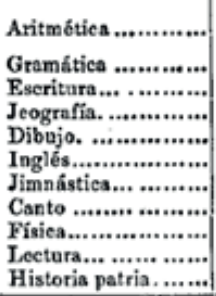 & 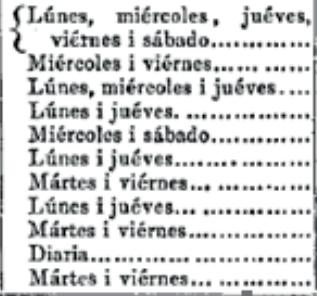 & 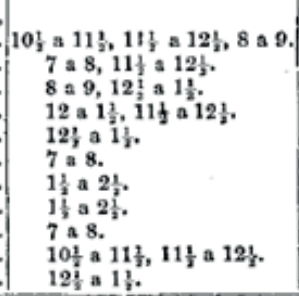 & $\begin{array}{l}\text { Bntran a las } \\
7 \text { i a las 10/ } \\
\text { de la mañans. } \\
\text { Salida a las } 9 \\
\text { i } 2 \text {. }\end{array}$ \\
\hline
\end{tabular}

ESCUELA INFRRIOR (38 ALUMNOS).

\begin{tabular}{|c|c|c|c|}
\hline ENSEF̂XZAS. & $D I \Delta s$. & I O X A s. & $\begin{array}{l}\text { ENTRADA } \\
\text { I SALIDA. }\end{array}$ \\
\hline $\begin{array}{l}\text { Gramática. ............ } \\
\text { I eetura i eseriturs.... } \\
\text { Jeografín................ } \\
\text { Cáleulo............... } \\
\text { Dibujo................ } \\
\text { Jimbástica............. }\end{array}$ & 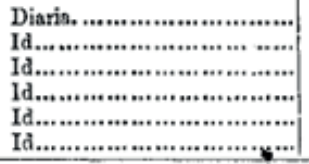 & $\begin{array}{l}7 \text { a } 8,8 \text { a } 9 . \\
7 \text { a } 8,8 \text { a } 9 . \\
11 \frac{2}{2} \text { a } 12 \frac{1}{4} \\
10 \frac{1}{3} \text { a } 11 \frac{1}{r} \\
12 \frac{1}{2} \text { a } 1 \frac{1}{3} . \\
1 \frac{1}{2} \text { a } 2 \frac{5}{5} .\end{array}$ & $\begin{array}{l}\text { Batran a las } \\
7 \mathrm{i} \text { a las } 10 \\
\text { de la mañana. } \\
\text { Salida a las } 9 \\
\text { i } 2 \frac{1}{\text {. }}\end{array}$ \\
\hline
\end{tabular}


En 1876 en la ciudad de Bogotá, la Guía de los directores i directoras de las escuelas públicas del Estado de Cundinamarca. Sistema Moderno de Enseñanza Primaria, de Romualdo Guarín (1876), proponía la instrucción pública fundada en los principios practicados por Pestalozzi desde la cual se daba importancia a introducir "en las escuelas primarias [...] las 'artes del dibujo' [a la vez que] toda materia de enseñanza debería principiar con la acción del pensamiento" (p. 129). Además, se resaltaba que las materias escolares que se enseñaban en la escuela debían estar en relación con el lugar que posiblemente los alumnos ocuparan más adelante en la sociedad.

Por ende, el dibujo fue comprendido como un ramo de instrucción y un medio aparente para "conseguir la actividad observadora i la vigorizacion de la intelijencia; da a la educacion intelectual la importancia que merece, i procura habilidad a ciertas partes del sistema orgánico, i amenidad i recreo a la enseñanza" (Guarín, p. 180). Estos argumentos sirvieron de fundamento para que se enunciara que no había razón para suprimirlo de las escuelas elementales, pues era tan importante como lo era el canto; simplemente, había que darle la dirección debida. Con la enseñanza de estos saberes, no se perseguía la constitución de geómetras o dibujantes exactos, sino que estuvieran en la capacidad de distinguir las figuras entre sí, que las imitaran e hicieran de ellas "una vulgar i desaliñada descripcion que no que definan sin discurrir, analizar ni comprender" (Guarín, p. 180).

Estas condiciones de posibilidad hacían pensar que, para este momento, el saber de las artes, en la forma del dibujo, se introducía e instalaba de modo permanente en la estructura escolar pública para complementar los ramos de instrucción y apoyar la escolarización e instrucción de los ciudadanos. En este sentido, la enseñanza del dibujo tuvo dos propósitos fundamentales:

1. Exitar la observacion i el armónico movimiento de las principales facultades del niño examinando i comparando la direccion i posicion absoluta i relativa de las líneas, las dimensiones de los trazados, i la forma, extension i magnitud de las superficies i volúmenes.

2. Lograr que los niños adquieran una nocion clara, más o ménos bien definida, de las ideas que examinen i comparen, i que su vista i su pulso se habitúen al trazado, con lo cual vaya adquiriendo vuelo la fureza imajinativa. (Guarín, p. 180)

Guarín (1876), destacó el valor del saber del canto como un ramo de enseñanza fundamental y un elemento poderoso para dar animación a las tareas escolares. Resaltaba que su aprendizaje debía contemplarse en la distribución del tiempo para una escuela elemental, que contribuye al desarrollo y fortificación de los pulmones de los niños. Se argumentó que todos los alumnos de la escuela debían aprender a cantar, a leer, a escribir, a rezar. Por tal razón:

Desde la primera semana de la entrada a la escuela aprenderán a cantar su cancioncita i los tonos de tónica- acorde 1, 3, 5 i 8, en órden ascendente i descendente; ademas, el primer tetracordio de la escala en dur, o modo mayor, i si fuere posible toda la escala. (p. 235)

Así, el saber del canto se instaló durante este periodo con mayor amplitud en la escuela pública para complementar los procesos de desarrollo intelectual y físico de los alumnos. Con ese fin, se propuso como contenidos de enseñanza, la diferenciación de tonos musicales, "distinguir con precision si un tono es igual a otro en cuanto a su altura; si suena más alto o más bajo, si sube o baja por grados o por intervalos" (Guarín, p. 235).

En otro sentido, el dibujo se introdujo en las escuelas primarias y elementales como el contenido preliminar con el que se debía comenzar la enseñanza de los niños, esto gracias a que en la época se afirmó que, era "tal vez la única enseñanza con la cual algunos niños ya traen ciertos conocimientos a la escuela" (p. 250). Además, porque era una enseñanza que manifestaba decidida tendencia entre los menores; era aquel ramo de la instrucción a través del cual se podían observar desde las primeras lecciones los adelantos y avances educativos logrados; era un referente para dar cuenta del progreso de los niños respecto de las otras materias, "lo cual les da animacion para estudiar i para que simpaticen con la escuela" (Guarín, p. 250).

Entre las canciones que se utilizaban para que los niños aprendieran el saber del canto estaba "El canto del niño", de la que se cantaba:

[...] el primer verso, del segundo solo se cantará el pasaje" que-al:" en seguida se procederá a la averiguacion. Pregúntese: - ¿Cómo suena al respecto de al?- Los niños responderán:-al, respecto de que, suena más alto.- ¿Cómo suena que respecto de al?-Más bajo. En lugar de cantar las sílabas que corresponden a los tonos que sirven para hacer el exámen, puede emplearse la sílaba la. Teniendo los niños la habilidad de distinguir entre los tonos alto, bajo e igual, podrán analizar con propiedad en una cancion la extructura de su melodía. (p. 236).

Respecto a la enseñanza del dibujo de líneas, figuras y cuerpos, entre otros, se enunció que su importancia radicaba en que contribuía a "observar la situacion, la forma i los detalles de los objetos, a 
medir las distancias i a apreciar las proporciones" (p. 25). Exigía, como cualquier otra materia escolar, un orden lógico que correspondía a la naturaleza de la materia misma, y a las dificultades que presentaba su aprendizaje a la inteligencia del alumno, en su comprensión como en su estructura material.

Para el caso de las escuelas elementales, (Guarín, 1876), se fijaron cinco medias horas por semana. Suficientes, pues en la clase objetiva maestro debía "dibujar siempre el objeto tratado, i de este modo los niños se ejercitan bastante en tan importante i dificil arte" (p. 249). Para la clase de dibujo en una escuela elemental, el pénsum, los contenidos de enseñanza se relacionaban para el año primero con:

1. Líneas rectas con sus diversas combinaciones.

2. Líneas oblicuas del mismo modo.

3. Líneas horizontales i combinaciones con ella.

4. Líneas curvas.

5. Líneas paralelas.

6. Combinaciones con todas esas líneas.

7. Triángulos, cuadriláteros, trapecios, diagonales, paralelogramo, rombo, cuadrilongo, cuadrado, pentágono, exágono.

8. Circunferencia, círculo, arco, cuerda, sajita, radio, diámetro, secante, tanjente.

9. Cubo, pirámides, prismas, conos, cilindros, esfera, círculos máximos, hemisferio, eje, polos, zonas, casquete, ángulo, círculos menores (p. 252).

Para el segundo año:

1. Definicion de la jeometría.

2. Explicacion de los términos i signos.

3. Los triángulos: rectángulo, equilátero, escaleno, isósceles i su construccion.

4. Dibujar figuras en que entran líneas rectas, por ejemplo, cruces de varias clases, estrellas \&c.

5. Las varias clases de cuadriláteros: trapecios paralelogramos.

6. Los paralelogramos: rombo, losanje, rectángulo, cuadrado.

7. Los polígonos regulares.

8. Pentágono, hexágono, decágono \&c.
9. Figuras con líneas curvas: circulo, elipse, óvalo, ovoide, espiral \&c.

10.Dibujo do plantas.

11.Paisajes sencillos.

12. Dibujo de máquinas i de otros objetos de uso doméstico.

13. Dibujo humano, de animales \&c (pp. 252-253).

Así, los saberes escolares como el dibujo, el canto y la música comenzaron a ser considerados ramos de enseñanza primordiales para "desarrollar las facultades del alma" (p. 99), y con ello, a enunciarse que "las artes mejoran los trabajos, y las gentes se modifican con el brillo de la civilizacion" (Díaz, 1878, p. 154). El canto, la música y el dibujo (lineal y de paisaje) se constituyeron entonces en saberes escolares dentro de la organización curricular de las escuelas y colegios públicos del país; especialmente, en las instituciones de formación de niñas. El dibujo, en particular, era necesario "para que sus bordados no [fueran] parches alegres, en vez de formas perfectas de pintura" (p. 167).

\section{El saber de las artes (1880-1900)}

En 1881, la incorporación del saber de las bellas artes había cobrado tanta importancia, no solo en el marco de la vida social sino de la estructura escolar pública. Por ello, la Secretaría de Instrucción Pública de la Unión (conformada por Estados Soberanos de Antioquía, Bolívar, Boyacá, Cauca, Cundinamarca, Magdalena, Panamá, Santander y Tolima) recomendaba asistir a la exposición nacional, en especial, a ver las exposiciones artísticas de los alumnos y maestros de los establecimientos de enseñanza, cuyo carácter se enfocaba en la exhibición de "muestras de dibujo, tomadas del natural o de grabados" (Pérez, 1881, p. 57), sobresalientes en el arte e influenciadas por el diseño, orientadas a "la formación del gusto i en la adquisición de ideas esactas, referentes a la forma, distancia, i tamaño relativo de los objetos" (Pérez, 1881, p. 57). También, muestras de piezas de música originales o copiadas por los maestros o los alumnos: "redaccion de un texto para la enseñanza del arte vocál e instrumental i, tambien, una memoria sobre la influencia de la música en la morijeracion de las costumbres i aptitudes" (p. 57). Sin embargo, adicionalmente se enseñaba "dibujo, canto, objetiva, calistenia, durante seis horas diarias distribuidas de las 6 a las 9 i de las 10 a la 1; i los métodos empleados en la enseñanza son por lo jeneral los modernos" (Paredes, 1881, p. 59). 
Por consiguiente, para finales del siglo XIX el saber de las bellas artes, las materias escolares de canto, música y dibujo se instalaba definitivamente en la escuela pública. Fueron apoyadas en las Escuelas Normales Nacionales de Institutores e Institutoras, donde se formaba a los candidatos a institutores en saberes como música, canto y dibujo, quienes, al ejercer su oficio, transmitían los conocimientos de las artes allí aprendidas.

Según lo expuesto en La Escuela. Revista Oficial de la Instrucción Pública en el Tolima, la educación se constituía en "una grandeza que compensa muchas miserias" (Prévost-Paradol 1880, p. 15). Con ello, el dibujo, la música y el canto se instalaban como materias de enseñanza articuladas a los ramos de instrucción pública a incluir en los procesos de enseñanza de los alumnos. Justamente, en la Escuela Normal del Tolima, entre las materias de enseñanza que se sometían a examen público estaban el dibujo, "música i canto" (Suárez, 1880, p. 31).

Como se ve, entre los saberes escolares que conservaban su estatus dentro de la organización curricular de la escuela se encontraban lectura, escritura, aritmética, gramática, geografía e historia patria y, por supuesto, dibujo, canto y música. Estos se instalaron acoplados a dichos saberes de la enseñanza en la escuela pública, a los que se asignaron maestros para que los enseñaran, y contribuyeron con ello a la formación de subjetividades escolares obedientes respecto al orden social y político establecido.

\section{E1 saber de las bellas artes a finales del siglo XIX}

Hacia 1892 se expidió la Ley 89 sobre instrucción pública, que le proponía a los estamentos territoriales en los que hubiera personal docente y elementos suficientes para su creación y sostenimiento, el establecimiento de escuelas preparatorias en las de bellas artes, entre otras. Adicionalmente, se emitió el Decreto 0349 sobre instrucción pública, que la dividió en departamental, asociada a la primaria o de primeras letras; y nacional, articulada con la secundaria y la profesional. En esta última norma también se declaró que formaban parte del ramo de Instrucción Secundaria, establecimientos como la Escuela de Bellas Artes, las Escuelas de Artes y Oficios y la Academia Nacional de Música, entre otros. Según el Decreto, la Escuela de Bellas Artes comprendía las secciones de estudio de geometría aplicada y de perspectiva; anatomía artística, actitudes humanas y fisonomía de las pasiones; dibujo y pintura a la aguada; pintura al óleo; ornamentación; teoría general de la arqui- tectura, dibujos, planos y proyecciones arquitectónicas; escultura, grabado en madera, esencialmente (Decreto 349 de 1892).

No obstante, respecto a la Escuela Nacional de Música, se declaró que las materias de enseñanza estarían enfocadas al canto, música teórica y práctica en instrumentos musicales como piano, órgano, violín, viola, violoncelo, contrabajo, clarinete, fagot, oboe, flauta, tromba, trompeta y trombón; como también, la enseñanza de la armonía, contrapunto, fuga e idioma italiano (Decreto 349 de 1892).

Para 1893, se emitió el Decreto 0429, por el cual se organizó la instrucción pública primaria. En él se expresó que las escuelas tenían por objeto formar hombres instruidos suficientemente en los conocimientos elementales, sanos de cuerpo y de espíritu, dignos y capaces de ser ciudadanos útiles al país. Asimismo, resaltaba que la enseñanza en las escuelas no se limitaría a la instrucción, sino que comprendería el desarrollo armónico de las fuerzas del cuerpo, de los sentidos y de todas las facultades del alma.

En dicho decreto se declaró, además, que durante los exámenes los alumnos expondrían, al inspector provincial los ejercicios de composición, planas y muestras de dibujo ejecutados en el periodo escolar, quien enviaba al secretario de instrucción pública del departamento aquellos que en su concepto eran los más notables.

Como se observó, durante la segunda mitad del siglo XIX se gestaron las condiciones para que el saber de las artes, en el modo de dibujo, canto y música se instalaran definitivamente en la estructura de los planes de enseñanza de la escuela pública colombiana para legitimar ciertos contenidos de enseñanza y con el propósito de contribuir en los procesos de escolarización infantil y constituir subjetividades escolares acordes a la racionalidad disciplinaria de la época.

\section{Reflexiones finales}

Durante la segunda mitad del siglo XIX, el saber de las artes, en la forma de las bellas artes (música, dibujo, canto), se introdujo e instaló en el andamiaje curricular de la escuela pública del país. Luego adoptó diversas formas y funciones, y operó conforme a las reglas de funcionamiento de cada momento histórico, que se emplearon para normar la enseñanza y la formación disciplinaria de las subjetividades escolares. Estas, por su parte, aprendieron a apreciar la belleza y la armonía mediante la observación de la naturaleza; a ser sensibles y a copiar y plasmar fielmente de ella la hermosura de sus objetos, como también, a utilizarlos como vehículos para la expresión de sus emociones y sentimientos. 
Todo ello, permitió dilucidar que los saberes de las artes irrumpieron en la escuela como fluctuaciones para transformar sus planes de enseñanza, sus estrategias, así como los mecanismos de poder para devenir sujetos.

En consecuencia, el estudio y exploración por la historia del saber de las artes en la escuela pública, en particular de la segunda mitad del siglo XIX, se convirtió en una posibilidad para cuestionar su presente. A la vez que indagó por su lugar en la estructura curricular escolar en la contemporaneidad, debido a que se tendió a naturalizar su existencia y presencia o se consideró que su aparición en los planes de estudio obedeció a una época más reciente.

Este ejercicio permite comprender las posturas contemporáneas respecto al saber de la educación artística, enfocadas a comprender la complejidad de las dinámicas sociales y culturales. Finalmente, la exploración histórica del saber de las artes durante la segunda mitad del siglo xIX permitió dilucidar su papel como tecnología de poder, empleada en el marco de la estrategia de la instrucción pública y del proyecto civilizador republicano para singularizar, adiestrar y someter a los individuos escolares y constituirlos conforme a la racionalidad de la época.

\section{Referencias}

Agudelo, A. (1858). Lecciones de música precedidas de una introducción histórica, seguida cada una de su respectivo programa. Bogotá: Imprenta de Pizano y Pérez. https:// repository.eafit.edu.co/handle/10784/1108

Barreto, I. (1856). Certamen público de la escuela primaria de niños de la Parroquia de Tasco. Bogotá: Imprenta de Francisco Torres. http://catalogoenlinea.bibliotecanacional.gov.co/client/es_ES/search/asset/75539/0

Cámara Provincial de Bogotá. Ordenanza 117 de 24 de octubre de 1850. Dando nueva planta al Colejio de la Merced. Bogotá: Autor.

Cárdenas, 0. y Cárdenas, M. (2019). La historia de los saberes artísticos en la escuela pública colombiana en la primera mitad del siglo xIX. Pedagogía y Saberes, 50, 173-185.

Castro, E. (2011). Diccionario de Foucault. Temas, conceptos y autores. Buenos Aires: Siglo xxi Editores.

Castro-Gómez, S. (2015). Historia de la gubernamentalidad I. Razón de Estado, liberalismo y neoliberalismo en Michel Foucault. Bogotá: Siglo del Hombre Editores.
Chervel, A. (1991). Historia de las disciplinas escolares. Reflexiones sobre un campo de investigación. Revista de Educación, 295, 39-59. http://www.mecd.gob.es/dctm/ revistaeducacion/numeros\%20 completos/re295. pdf?documentId=0901e72b8130f412

Cuarto Informe actual del Director de Instrucción pública del Estado Soberano de Cundinamarca. (1874). Bogotá: Imprenta de Echeverry Hermanos. https://bibliotecanacional.gov.co/content/conservacion?idFichero $=70120$

Díaz Castro, Eugenio. (1878). Capítulo X. La siega. En El rejo de enlazar. Obras inéditas originales (pp. 152-167). Bogotá: Imprenta La América. http://catalogoenlinea.bibliotecanacional.gov.co/client/es_ES/search/ asset/88026/0

El Ciudadano. Periódico de la Juventud. (1850, 30 de junio). Instrucción pública, trim. 1(3), 3. http://catalogoenlinea.bibliotecanacional.gov.co/client/es_ES/search/ asset/158744

El Constitucional de Cundinamarca. (1846, 3 de octubre). Visita de las escuelas. No. 185. http://babel.banrepcultural.org/cdm/compoundobject/collection/ p17054coll26/id/1883/show/1732/rec/8

El Constitucional de Cundinamarca (1848, 20 de abril). No oficial. Agricultura. No. 238. https://catalogoenlinea. bibliotecanacional.gov.co/client/es_ES/search/asset/127752El Constitucional de Cundinamarca (1850, 7 de diciembre). Ordenanza 117. No. 283. https://catalogoenlinea.bibliotecanacional.gov.co/client/es_ES/ search/asset/127778El Museo (1849, 15 de abril). Mal uso de algunas palabras. I (2). http://catalogoenlinea.bibliotecanacional.gov.co/client/es_ES/search/ asset/159173

Foucault, M. (1990). Tecnologías del yo y otros textos afines. Barcelona: Ediciones Paidós Ibérica, S.A.

Foucault, M. (2004). Seguridad, territorio, población. Curso en el Collège de France (1977-1978). México: Fondo de Cultura Económica.

Foucault, M. (2017). Obras esenciales. Barcelona: Ediciones Paidós.

Goodson, I. (1991). La construcción social del currículum. Posibilidades y ámbitos de investigación de la historia del currículum. Revista de Educación, 295, 7-39. http://www.mecd.gob.es/dctm/revista-de-educacion/numeros\%20 completos/re295. pdf?documentId=0901e72b8130f412

Guarín, R. (1876). Guía de los directores i directoras de las escuelas públicas del Estado de Cundinamarca. Sistema Moderno de Enseñanza Primaria. Bogotá: Imprenta de Gaitán. http://catalogoenlinea.bibliotecanacional.gov. co/client/es_ES/search/asset/80825/0 
Hernández T., E. (26 de enero de 1868). El canto. La Aurora. Ensayos de Literatura. 1(2), 121. Cartagena. http:// babel.banrepcultural.org/cdm/compoundobject/ collection/p17054coll26/id/2849

Informe del Ministro de Instrucción Pública presentado al Congreso de la República en sus sesiones ordinarias de 1872. (1872). Centro Virtual de Memoria en Educación y Pedagogía, IDEP. Bogotá. http:// www.idep.edu.co/wp_centrovirtual/wp-content/ uploads/2015/09/1872\%20-\%20Informe\%20del\%20 Ministro\%20de\%20Instrucci\%C3\%B3n\%20P\%C3\%BAblica\%20al\%20Congreso\%20de\%20Colombia.pdf

Jaramillo, J. (1980). Decreto Orgánico de Instrucción Pública de 1870. Revista Colombiana de Educación. 5 (I). https://revistas.pedagogica.edu.co/index.php/ RCE/article/view/5024/4110

La Escuela Normal. (1871, 7 de enero). Decreto Orgánico de la Instrucción Pública Primaria. Periódico Oficial de Instruccion Pública, 1(1), 2-9. https://babel.hathitrust.org/ cgi/pt?id=umn.31951000971501h\&view=1up\&seq=12

La música. (23 de enero de 1858). Biblioteca de Señoritas, 4, año 1, 29-30. http://babel.banrepcultural.org/cdm/ compoundobject/collection/p17054coll26/id/3351/ rec/11

Los RR (1867, 8 de junio). Una felicitación. La Aurora. Ensayos de Literatura, 1(2). http://babel.banrepcultural. org/cdm/compoundobject/collection/p17054coll26/ id/2849

Martínez Boom, A. (2004). De la Escuela Expansiva a la Escuela Competitiva. Barcelona: Antropos Editorial.

Ministerio de Educación Nacional. (1893, 11 de enero). Decreto 349 de 1892. Diario Oficial No. 9041 https://normograma.info/men/docs/pdf/decreto_0349_1892.pdf

Ministerio de Educación Nacional. (1893, 12 de febrero). Decreto 429 de 1893. Diario oficial No. 9073. https:// www.mineducacion.gov.co/1621/article-102506.html

Ortiz, J. J. (1853). Programa de Enseñanza del Instituto de Cristo. Bogotá: Imprenta de Nicolás Gómez. http://catalogoenlinea.bibliotecanacional.gov.co/client/es_ES/ search/asset/73560/0

Plan de las Escuelas Patrióticas. (1808, 13 de marzo). Semanario del Nuevo Reyno de Granada. Santafé. No. 11. Santafé. http://babel.banrepcultural.org/cdm/ compoundobject/collection/p17054coll26/id/1655/ show $/ 1545 / \mathrm{rec} / 36$

Paredes, A. M. (1881, 15 de abril). Informe del Inspector del Departamento del Sur. La Escuela. Revista Oficial de la Instrucción Pública en el Tolima, I (15), 59. http://catalogoenlinea.bibliotecanacional.gov.co/client/es_ES/ search/asset/160288
Pérez, R. (1881, 15 de abril). Circular a los directores, superintendentes e inspectores de Instrucción pública. La Escuela. Revista Oficial de la Instrucción Pública en el Tolima, I(15), 57. http://catalogoenlinea.bibliotecanacional.gov.co/client/es_ES/search/asset/160288

Pinzón, C. (1864). Catecismo Republicano para instruccion popular, redactado a escitacion del ciudadano presidente de los Estados Unidos de Colombia, destinándolo con especialidad a las escuelas de los cuerpos de la guardia colombiana, creadas por el decreto presidencial de 1.o de setiembre de 1864. Bogotá: Imprenta de "El Mosaico". http://catalogoenlinea.bibliotecanacional. gov.co/client/es_ES/search/asset/73443/0

Prévost-Paradol, M. (1880, 30 de octubre). Del papel que desempeña la familia en la educación. La Escuela. Revista Oficial de la Instrucción Pública en el Tolima. I(4). Neiva. https://catalogoenlinea.bibliotecanacional. gov.co/client/es_ES/search/asset/160324

República de Colombia. (1892, 24 de diciembre). Ley 89 de 1892 sobre instrucción pública. Diario Oficial No. 9023. https://normograma.info/men/docs/pdf/ ley_0089_1892.pdf

Suárez, M. A. (1880, 31 de diciembre). Copia de los diplomas expedidos en la Escuela Normal Nacional del Tolima. La Escuela. Revista Oficial de la Instrucción Pública en el Tolima, I(8), 31. http://catalogoenlinea.bibliotecanacional.gov.co/client/es_ES/search/asset/160294

Triana, J. M. (1845). Manual de Enseñanza Mutua para las Escuelas de Primeras Letras. Bogotá: J. A. Cualla. http:// catalogoenlinea.bibliotecanacional.gov.co/client/ es_ES/search/asset/73667/0

Triana, J.M. (1851). Manual para los preceptores de enseñanza primaria, e instrucción moral i religiosa, adaptado para las escuelas de la provincia de Bogotá. Bogotá: Imprenta del Neo-Granadino. http://catalogoenlinea.bibliotecanacional.gov.co/client/es_ES/search/ asset/78956/0

Vargas de la Rosa, V. (1882). Teoría de Música. Bogotá: Imprenta de Medardo Rivas. http://www. idep.edu.co/wp_centrovirtual/wp-content/ uploads/2015/12/1882\%20-\%20Teoria\%20de\%20 la $\% 20$ Musica $\% 20$ por $\% 20$ Vicente $\% 20$ Vargas $\% 20$ de\%20la\%20Rosa.pdf

Zuluaga, O. L. (1998). La educación pública en Colombia (1845-1875). Libertad de enseñanza y adopción de Pestalozzi en Bogotá. Medellín/Bogotá, Colombia: Facultad de Educación Universidad de Antioquía, Instituto de Investigación Educativa y Desarrollo Pedagógico (IDEP). http://www.idep.edu.co/wp_centrovirtual/ wp-content/uploads/2015/12/La\%20educacion $\% 20$ publica\%20en\%20Colombia\%201845-1875.pdf 